Prosiding Seminar Nasional Teknologi Informasi dan Kedirgantaraan : Transformasi Teknologi untuk Mendukung Ketahanan Nasional, Yogyakarta, 13 Desember 2018

SENATIK 2018, Vol. IV, ISBN 978-602-52742-0-6

DOI: http://dx.doi.org/10.28989/senatik.v4i0.144

\title{
NUMERICAL ANALYSIS DISCONTINUITY OF THIN WALLED TUBE SUBJECTED LOW VELOCITY IMPACT Bismil Rabeta $^{1)}$, Sahril Afandi Sitompul') \\ Fakultas Teknologi Dirgantara \\ Universitas Dirgantara Marsekal Suryadarma \\ Jl.Protokol Halim Perdanakusuma Komplek Bandara Halim Perdanakusuma Jakarta,13610 \\ Email : ${ }^{1}$ bismilrabeta@yahoo.co.id, ${ }^{2}$ sahrilxy@yahoo.com
}

Abstract
Car accidents have increased significantly for countries that have high gross domestic product (GDP) [1]. This has fatal consequences for passengers, especially if there is an accident at the front of the vehicle [3]. To minimize the impact of accidents on the front of the vehicle, the bumper system on the vehicle must be designed as well as possible. The bumper system is equipped with an collision absorbing system called the crash box. This system is mounted on the front and rear part of the vehicle and consist of a frontal bar and longitudinal members. Longitudinal members have the shape of thin walled tubes. During collision, the frontal bar is directly in contact with the source of impact energy and it distributes the load to the thin walled tube. The thin walled tube will receive the peak crushing force from the source of collision energy and absorb the energy by plastic deformation. The deformation behavior of the thin walled tube determines the crashworthiness of the vehicle. In the crushing box design, the thin walled tube can be given discontinuity in the form of a circular hole has been done by previous reseachers to find out how much peak force caused by collision with some variations. In this research, numerical analysis conducted using the thin walled tube with ellipse discontinuity by varying the ratio of ellipse hole in the crushing box to D/b ratio 0.0, 0.2, 0.3, 0.5. The analysis is conducted to compare the peak crushing force occur in D/b ratio for ellips discontinuity. The result of the research prove that the tube with $\mathrm{D} / \mathrm{b} 0.0$ has the highest peak crushing force than the other ratio.

Keyword: Bumper, crash box, frontal bar, longitudinal members, peakforce.

\section{Abstrak}

Kecelakaan mobil meningkat tajam untuk Negara-negara yang mempunyai pendapatan perkapita yang tinggi[1] . Hal ini berakibat fatal bagi para penumpang khususnya apabila mengalami kecelakaan pada bagian depan kendaraan[3]. Untuk meminimalisir dampak yang terjadi akibat kecelakaan pada bagian depan kendaraan, maka sistem bumper pada kendaraan harus didisain sebaik mungkin. Pada bagian bumper dilengkapi oleh sistem penyerap tumbukan yang disebut dengan crash box. Sistem ini dipasang pada bagian depan dan belakang kendaraan dan terdiri dari frontal bar dan longitudinal members. Longitudinal members sering disebut juga tabung berdinding tipis berdasarkan dari bentuknya. Pada saat terjadi tumbukan, frontal bar akan kontak secara langsung dengan sumber energi tumbukan dan meneruskannya ke tabung berdinding tipis. Tabung berdinding tipis akan menerima peak crushing force dari sumber energi tumbukan dan menyerap energi tumbukan dengan cara berdeformasi plastis. Perilaku tabung berdinding tipis dalam menyerap energi tumbukan akan menentukan crashworthiness suatu kendaraan. Pada disain crushing box, tabung dapat diberi diskontinuitas berupa lubang yang berbentuk lingkaran yang telah dilakukan oleh peneliti sebelumnya untuk mengetahui seberapa besar peak crushing force akibat tumbukan yang 
dialami pada tabung tersebut dengan beberapa variasi. Pada penelitian ini dilakukan analisis simulasi numerik menggunakan diskontinuitas tabung berbentuk elips dengan memvariasikan rasio lubang pada tabung crushing box menjadi rasio $\mathrm{D} / \mathrm{b}$ 0.0, 0.2, 0.3 dan 0.5. Hasil dari penelitian ini didapatkan penggunaan tabung crushing box dengan rasio D/b 0.0 memiliki nilai peak crushing force tertinggi dibandingkan dengan variasi tabung dengan rasio $\mathrm{D} / \mathrm{b}$ lainnya.

Kata Kunci : Bumper, crash box, frontal bar, Longitudinal members, peak force.

\section{Pendahuluan}

Tingginya peningkatan jumlah kendaraan bermotor terjadi setiap tahun sehingga memicu kepadatan lalu lintas dan tingkat kecelakaan. Oleh sebab itu, jumlah korban jiwa meningkat tiap tahunnya. Berdasarkan hasil prediksi TFEC (Traffic Fatalities and Economic Growth), pada tahun 2000 hingga 2020, Asia Selatan diperkirakan tercatat sebagai pemilik angka kematian tertinggi akibat kecelakaan, dengan peningkatan sebesar $144 \%$ terutama di negara-negara yang memiliki pendapatan tinggi ${ }^{[1]}$.

Tingkat persentase kecelakaan mobil yang tinggi tersebut terjadi berdasarkan berbagai jenis variasi tabrakan. Tabrakan dari arah bagian depan memiliki persentase paling tinggi hingga mencapai sekitar $60 \%$. Gambar 1, menunjukkan persentase dari tiap jenis tabrakan dimana jenis tabrakan ini sering terjadi karena kepadatan arus lalu lintas yang tinggi. Jenis tabrakan ini terjadi akibat tabrakan dengan mobil lain maupun tabrakan dengan benda-benda lain.[3]

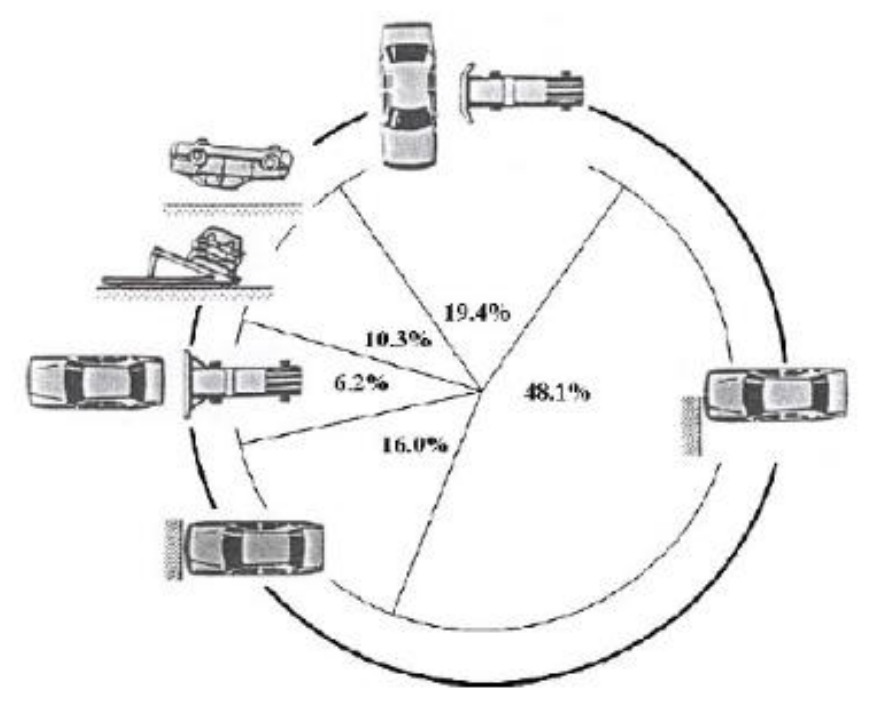

Gambar 1. Distribusi kecelakaan mobil di dunia berdasarkan tipe tabrakan[4]

Untuk melindungi penumpang yang berada di dalam mobil, saat ini banyak fitur keselamatan baru seperti airbags, bumper, crush box, seat belts, dan ABS brakes. Bumper dan crash box berguna untuk melindungi kabin penumpang dari tabrakan arah depan struktur mobil. Design dan produksi dari sebuah bumper harus dilakukan secara teliti guna menghasilkan ketahanan bumper yang maksimal

Bumper seperti ditunjukkan pada Gambar 2. merupakan salah satu kunci utama pada suatu struktur mobil, dimana bumper memiliki peran penting untuk mengurangi dampak tabrakan mobil. Bumper terdapat pada bagian depan dan belakang kendaraan. Sistem ini terdiri dari frontal bar dan longitudinal members yang bekerja menyerap energi akibat tabrakan dengan cara berdeformasi. Frontal bar akan langsung berinteraksi dengan sumber 
tumbukan, yang selanjutnya akan diteruskan ke longitudinal members. Longitudinal members inilah yang sering disebut dengan istilah crushing box.

Crushing box adalah struktur yang didesain untuk menyerap energi tubrukan menjadi deformasi plastis berupa wrinkling dan buckling terutama pada kasus tumbukan longitudinal. Apabila terjadi tumbukan dan crushing box tidak berdeformasi, maka beban tumbukan ini akan langsung diteruskan ke daerah kabin penumpang, dan dapat diperkirakan penumpang akan langsung merasakan beban tumbukannya. Disamping merasakan beban tumbukan, keselamatan penumpang pun terancam. Oleh karena itu, diharapkan seluruh energi tumbukan dapat diserap menjadi kerusakan plastis pada struktur crushing box. Tujuan penelitian ini adalah untuk menentukan harga peak crushing force akibat pengaruh diskontinuitas dari tabung yang berbentuk elips dengan variasi $\mathrm{D} / \mathrm{b}$ 0.0, $0.2,0.3$ dan 0.5 .

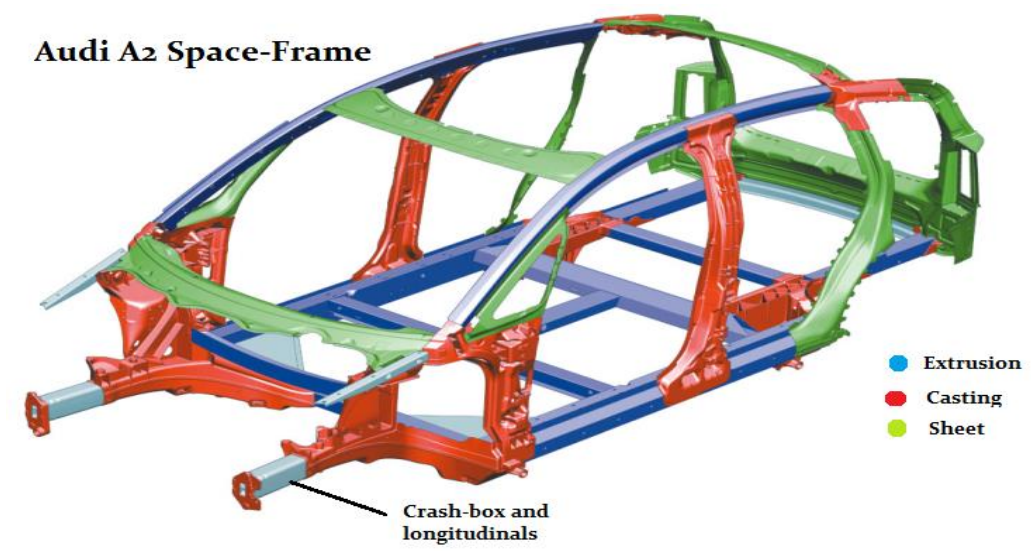

Gambar 2. Struktur bumper kendaraan ${ }^{[4]}$

\section{Metodologi Penelitian}

Penelitian yang akan dikerjakan merupakan simulasi numerik yang memanfaatkan perangkat lunak Abaqus 6.14 untuk mengetahui modus deformasi tabung dan harga peak crushing force yang terjadi pada tabung apabila mengalami beban tumbukan kecepatan rendah dengan variasi diskontinuitas elips dengan $\mathrm{D} / \mathrm{b} 0.0,0.2,0.3$, dan 0.5.

Seperti yang diperlihatkan pada gambar 3, geometri struktur crush box atau tabung berdinding tipis terdiri dari lebar sisi tabung (b), tinggi tabung (L), ketebalan tabung (t) dan untuk diameter elips yang digunakan adalah diameter sumbu utama (major axis) (D), dimana perbandingan diameter sumbu utama dengan sumbu minor (minor axis(a)) adalah 2 seperti yang ditunjukkan pada gambar 4.

Pada tabel 1, ditunjukkan variasi geometri pada tabung diskontinuitas elips. Simulasi dilakukan sebanyak tiga kali dengan variasi D/b dan kecepatan. Sedangkan untuk lebar, ketebalan, ketinggian memiliki harga yang tetap. 


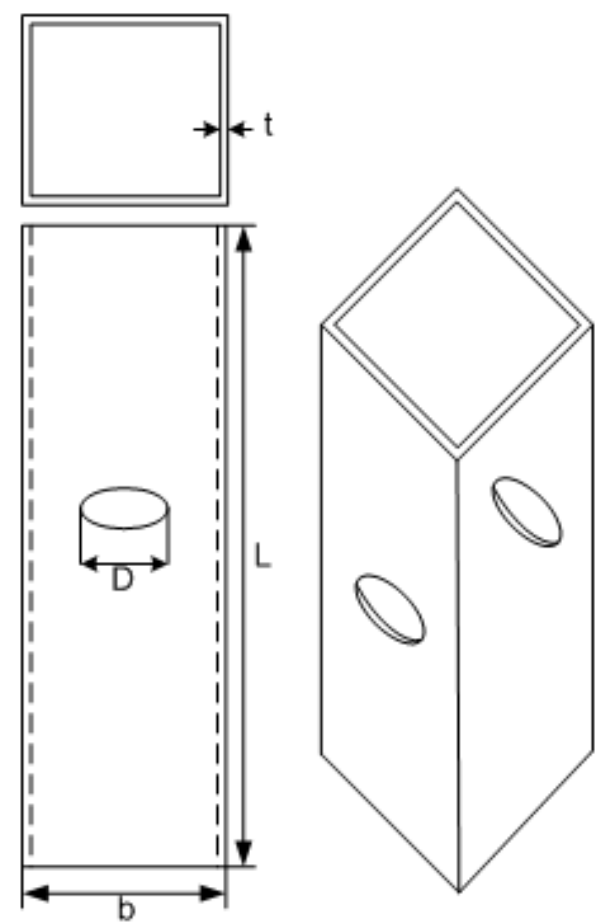

Gambar 3. Geometri struktur Crush Box

Tabel 1. Geometri simulasi tabung persegi panjang dengan efek diskontinuitas elips

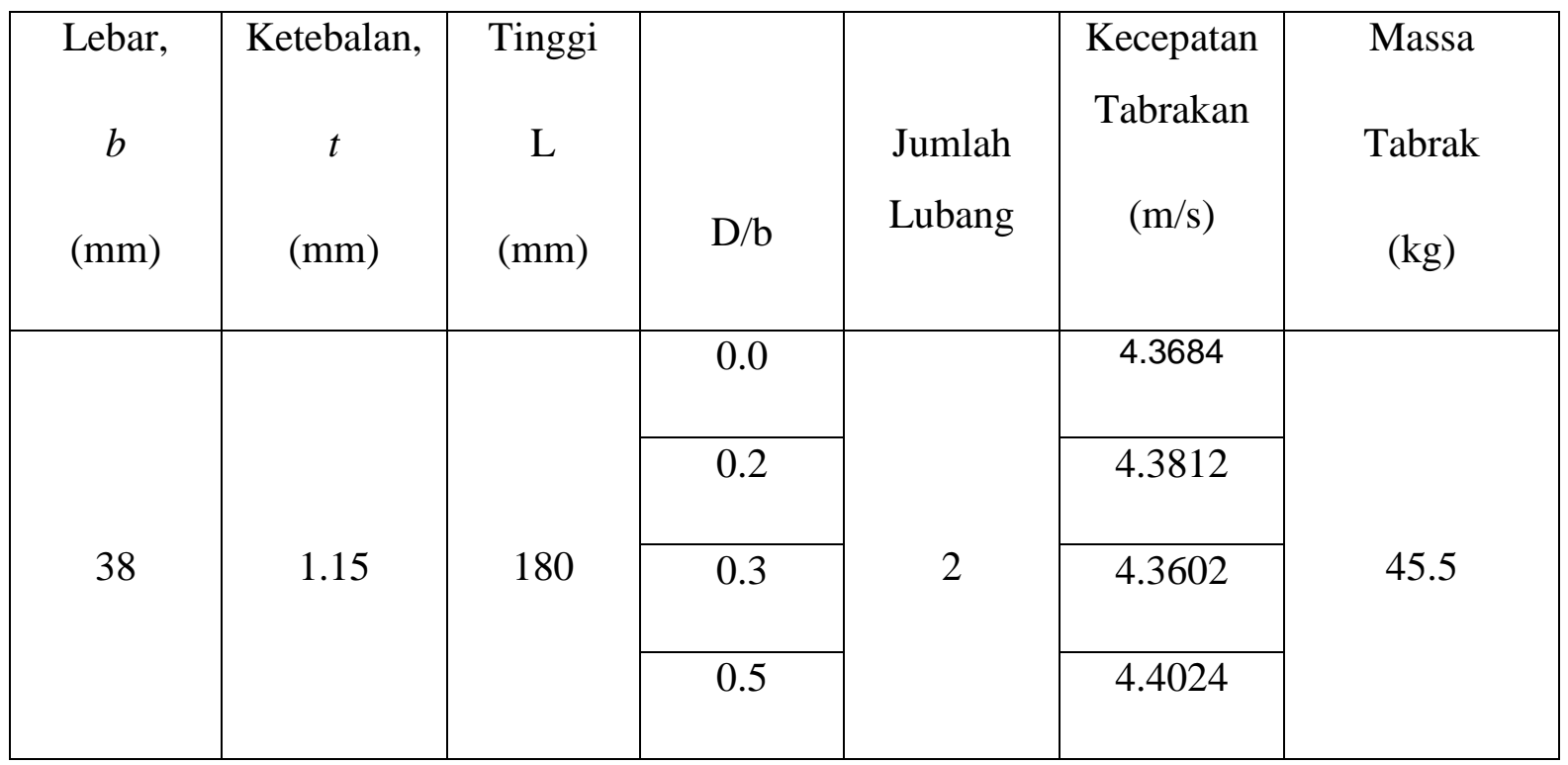

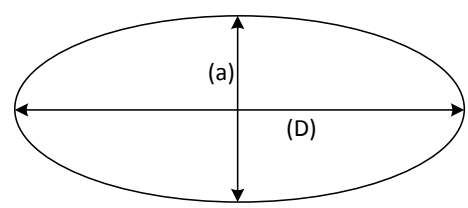

Gambar 4. Perbandingan diameter sumbu utama (D) dengan diameter sumbu minor (a) pada variasi lubang elips 


\section{Data Material}

Alumunium banyak digunakan sebagai material struktur kendaraan baik roda dua, roda empat, struktur pesawat, dan macam-macam kendaraan lainnya. Untuk simulasi permodelan crush box harus dimasukan nilai massa jenis dan sifat elastisnya.

Material yang digunakan pada proses simulasi kali ini adalah material AA 6063-T1 untuk model crush box yang berupa tabung alumunium berdinding tipis

Tabel 2. Properti dari AA 6063-T1 [3]

\begin{tabular}{|c|c|}
\hline \multicolumn{2}{|c|}{ AA 6063-T1 } \\
\hline Young's modulus, E (Gpa) & 73.169 \\
\hline Tensile stress, $\sigma_{u}($ Mpa) & 154 \\
\hline Poisson's ratio, $\boldsymbol{v}$ & 0.3 \\
\hline Density, $\rho\left(\mathrm{kg} / \mathbf{m}^{\mathbf{3}}\right)$ & 2700 \\
\hline
\end{tabular}

\section{Hasil dan Pembahasan}

\section{Grafik Instantaneous Crushing Force}

Hasil simulasi numerik diperoleh dalam bentuk geometri dan material yang sama. Hasil simulasi numerik ini akan menunjukkan bentuk deformasi yang terjadi pada struktur crush box. Selain itu, dapat diperoleh instantaneous force (grafik yang menunjukkan gaya setiap displacement pada saat terjadinya tumbukan), serta peak crushing force yang merupakan nilai puncak gaya pada saat terjadinya tumbukan melalui mekanisme deformasi plastis. Simulasi tumbukan yang terjadi pada crush box menggunakan variasi rasio pada hole imperfection yaitu rasio D/b dari 0.0, 0.2, 0.3, dan 0.5. Hasil simulasi numerik dapat ditampilkan dalam bentuk data crushing force vs crushing length (force vs displacement).
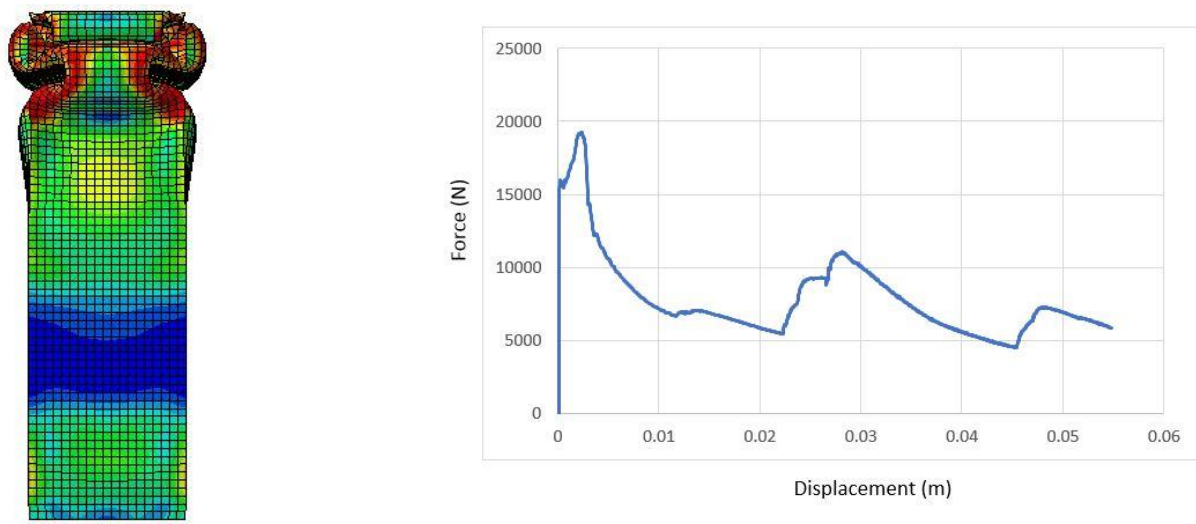

Gambar 5. Hasil mode deformasi dan grafik crushing force dari tabung crush box dengan $\mathrm{D} / \mathrm{b}=0.0$ 

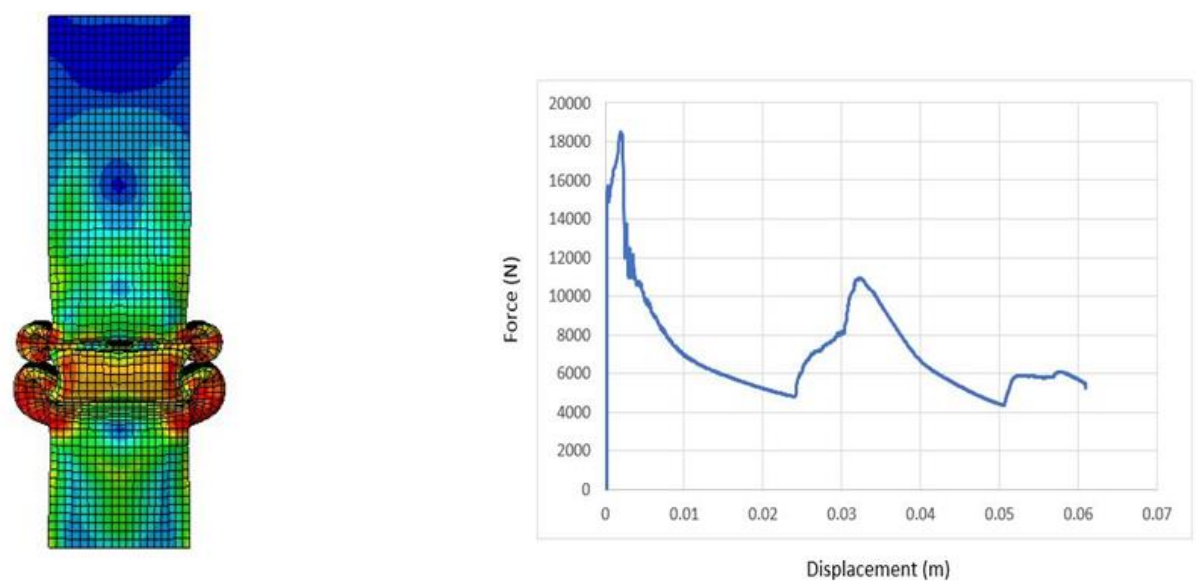

Gambar 6. Hasil mode deformasi dan grafik crushing force dari tabung crush box dengan $\mathrm{D} / \mathrm{b}=0.2$
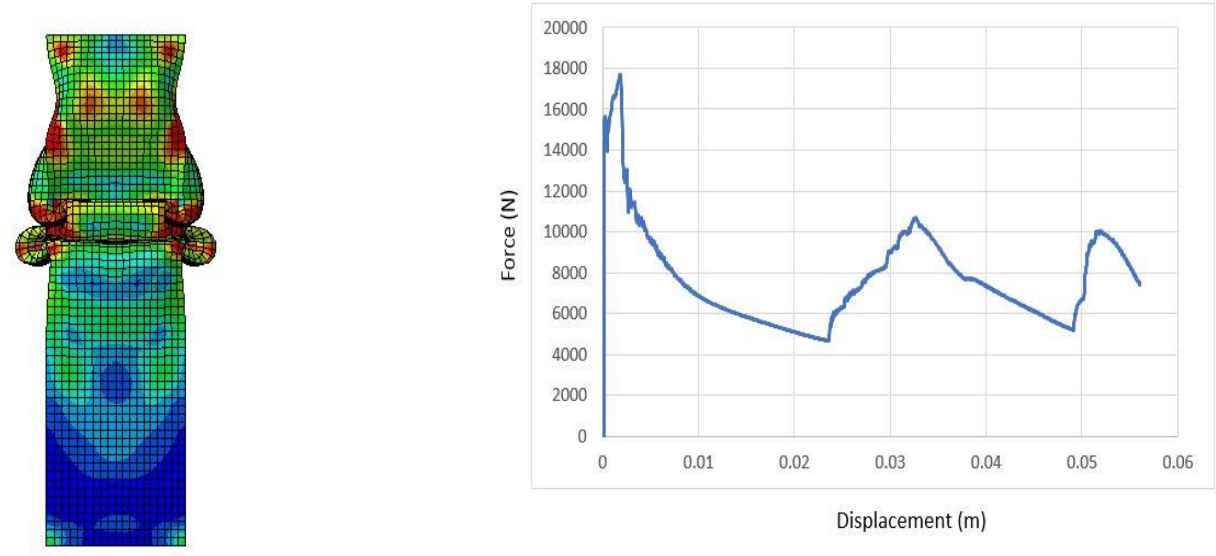

Gambar 7. Hasil mode deformasi dan grafik crushing force dari tabung crush box dengan $\mathrm{D} / \mathrm{b}=0.3$
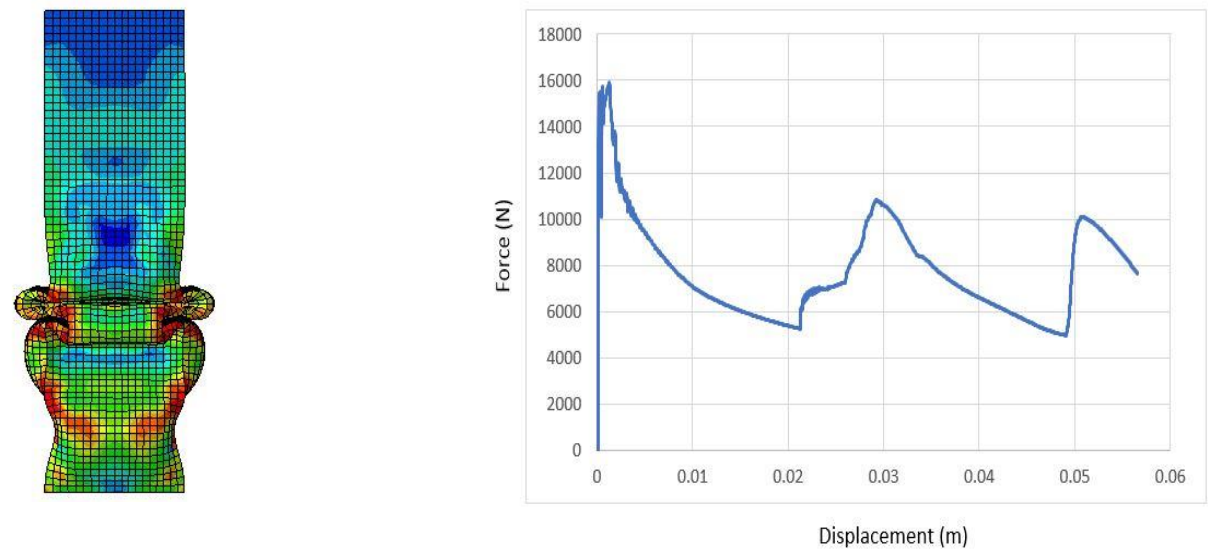

Gambar 8. Hasil mode deformasi dan grafik crushing force dari tabung crush box dengan $\mathrm{D} / \mathrm{b}=0.5$ 


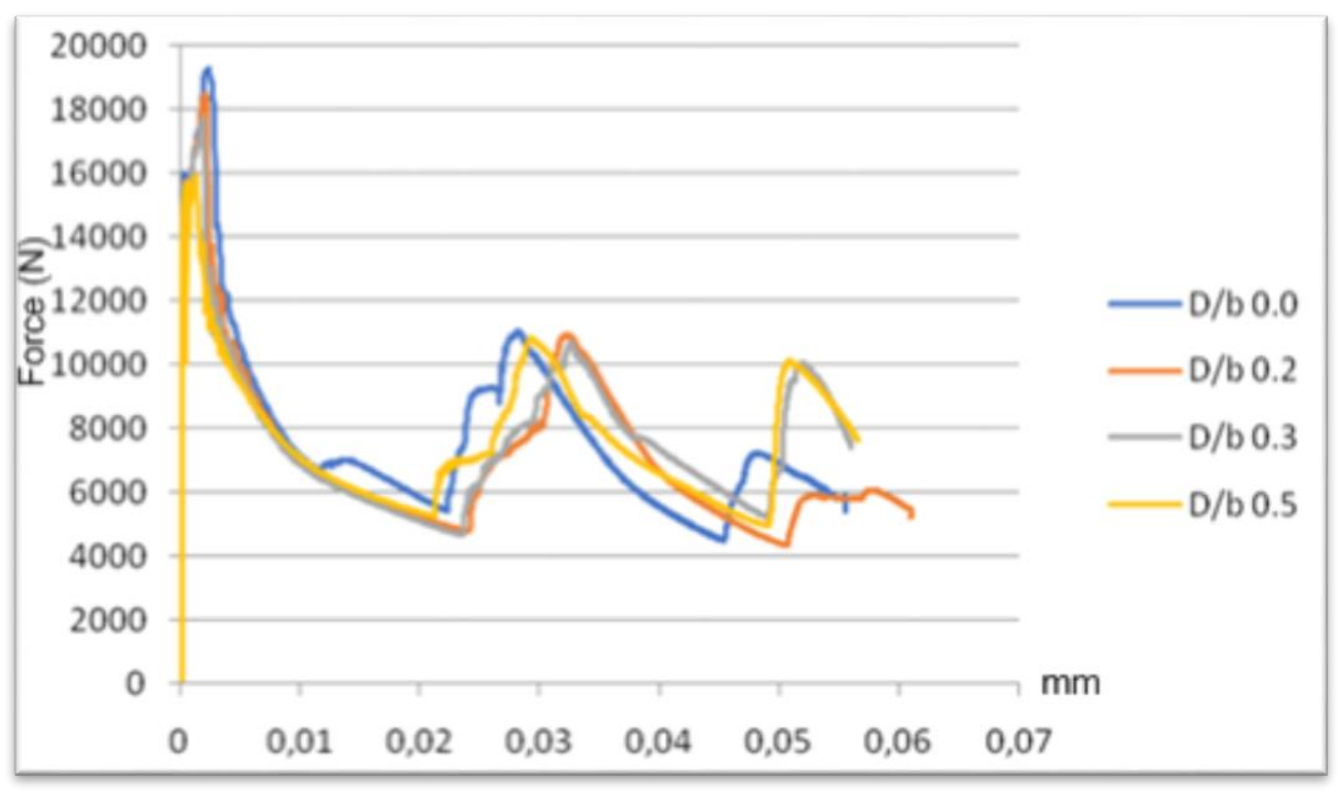

Gambar 9. Perbandingan grafik deformasi pada tabung crush box dengan lubang elips untuk rasio $\mathrm{D} / \mathrm{b} 0.0,0.2,0.3$, dan 0.5 .

Pada gambar 9. Merupakan grafik yang merangkum seluruh hasil force vs displacement yang ditunjukkan oleh gambar 5,6, 7 dan 8. Dapat dilihat dari gambar 8 bahwa semakin besar D/b ratio maka semakin kecil peak crushing force yang dihasilkan.

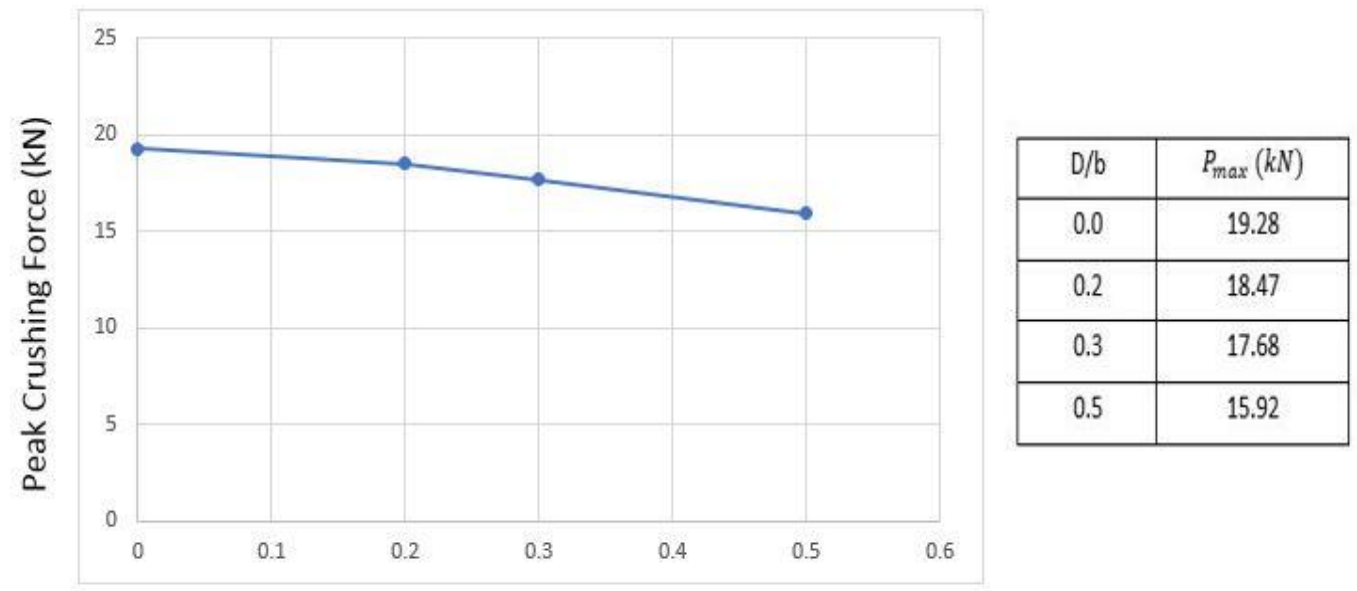

$\mathrm{D} / \mathrm{b}$

Gambar 10. Grafik Peak Crushing Force (P max) variasi rasio D/b pada tabung crush box dengan lubang berbentuk elips.

Pada gambar 10. Dapat dilihat bahwa untuk variasi $\mathrm{D} / \mathrm{b}=0$ memiliki nilai peak crushing force tertinggi sebesar $19.28 \mathrm{kN}$, sedangkan untuk peak crushing force terendah dihasilkan oleh variasi D/b 0.5 yaitu sebesar $15.92 \mathrm{kN}$

\section{Kesimpulan}

Hasil dari simulasi numerik didapatkan nilai peak force tertinggi dihasilkan oleh tabung dengan $\mathrm{D} / \mathrm{b}=0.0$, sedangkan peak force terendah dihasilkan oleh tabung dengan $\mathrm{D} / \mathrm{b}=$ 0.5. Sehingga dapat ditarik simpulan bahwasannya dengan $\mathrm{D} / \mathrm{b}$ yang semakin besar maka nilai peak force yang dihasilkan semakin kecil. Sehingga dengan menggunakan disain crush 
box dengan efek kontinuitas elips $\mathrm{D} / \mathrm{b}$ yang semakin besar dapat memperlambat terjadinya efek tumbukan terhadap tubuh penumpang yang mengendari mobil. Saran untuk penelitian selanjutnya agar hasil peak force dapat dibandingkan dengan tabung yang memiliki diskontinuitas lingkaran dengan variasi kecepatan dan D/b yang sama.

\section{Ucapan Terimakasih}

Terimakasih kepada pihak Ristek Dikti yang telah membantu terlaksananya pembuatan penelitian ini dalam hal materil, juga kepada LPPM yang senantiasa membantu menginformasikan hal-hal penting dalam penelitian ini. Tidak lupa kami ucapkan terimakasih kepada pihak STTA yang sudah menyelenggarakan acar SENATIK 2018.

\section{Daftar Pustaka}

[1] Peden, M. (2004), World report on road traffic injury prevention. Geneva, World Health Organization,

[2] World Health Organization (2009), Global Status Report On Road Safety;

[3] Dirgantara, T., Gunawan, Leonardo.,Putra, I.S (2013), Numerical and Experimental Impact Analysis of Square Crash Box Structure with Holes.

[4] Frank, T. dan Gruber, K. (1992), Numerical Simulation of Frontal Impact and Offset Collision; Cray Researc Inc., CRAY Channels:2-6 